\section{Compreendendo a prática do aleitamento exclusivo: um estudo junto a lactantes usuárias da Rede de Serviços em Fortaleza, Ceará, Brasil}

\section{Understanding exclusive breastfeeding practices: an exploratory study of lactating women using the Health Services Network in Fortaleza, Ceará, Brazil}

Márcia Maria Tavares Machado 1

Maria Lúcia Magalhães Bosi 2

\begin{abstract}
1,2 Departamento de Saúde Comunitária. Faculdade de Medicina. Universidade Federal do Ceará. Rua Prof. Costa Mendes, 1608, $5^{\circ}$ andar. Fortaleza, CE, Brasil. CEP: 60.140-120.
\end{abstract}

E-mail: marciamachado@pq.cnpq.br

\begin{abstract}
Objectives: this paper focus on perceptions and experiences of women who practiced exclusive breastfeeding for a minimum period of six months. We tried to understand their attitudes and what breastfeeding meant to them in an attempt to understand how this option took place and was maintained in the group making the decision of exclusive breastfeeding.

Methods: the study was oriented by social survey qualitative methodology, with an assessment and interpretative focus. The sample was comprised of 13 lactating mothers, users of the health services network of Fortaleza, State Ceará, Brazil. The technique of choice was in-depth individual interviews.

Results: the complexity of breastfeeding became evident, although many times considered natural and easy to be experienced independently from the social environment where it takes place. The role played by parents and grandparents was determined as being an important element in the breastfeeding process. This study concluded that successful breastfeeding was rooted in the concepts construed by the respondents throughout their lives and in their own experiences resulting in new interpretations of concepts prior to their breastfeeding experience, as well as in the events taking place during the experience.

Conclusions: such experiences are not only linked to the subjective level for they report to the dimension of real life where relationships with the healthcare professionals and services are established. Key words Exclusive breastfeeding, Qualitative research, Breastfeeding, Nutrition
\end{abstract}

\section{Resumo}

Objetivos: abordar percepções e vivências de mulheres que amamentaram exclusivamente por seis meses; retratar suas atitudes e o significado que a amamentação tem para elas, esclarecendo como se originou e se sustentou no grupo a prática da amamentação exclusiva.

Métodos: estudo qualitativo de investigação social, com enfoque crítico-interpretativo. A amostra foi composta por 13 lactantes, usuárias da rede de serviços de Fortaleza, Ceará, Brasil. A técnica utilizada foi a entrevista individual em profundidade.

Resultados: evidenciou-se a complexidade do ato de amamentar, muitas vezes naturalizado e considerado como possivel de ser vivenciado, independentemente do contexto social em que se desenvolve. O papel desempenhado pelos pais e avós mostrou-se um elemento importante no processo da amamentação. Constatou-se, que o sucesso do aleitamento materno teve como origem os significados construídos pelas informantes, ao longo de suas vidas e na própria vivência de lactante, na qual se processaram reinterpretações de concepções prévias às suas experiências com o ato de amamentar.

Conclusões: as experiências reportam à dimensão concreta da vida, na qual se inserem as relações estabelecidas com os serviços e os profissionais de saúde. A motivação e percepção do processo de amamentar ancoram-se em experiências inseridas em redes sóciofamiliares, construtoras de autoconfiança, resultando numa determinação, que superam, os diferentes obstáculos apresentados para a conquista da amamentação.

Palavras-chave Amamentação, Pesquisa qualitativa, Aleitamento materno, Nutrição 


\section{Introdução}

A presente investigação objetivou explorar concepções e vivências de mulheres que amamentaram exclusivamente seus filhos por seis meses, considerado pela Organização Mundial da Saúde (OMS) ${ }^{1}$ e pelo Ministério da Saúde do Brasil2 como recomendável no que se refere a essa prática.

As mulheres que amamentam durante esse período demonstram grande determinação, conseguindo superar muitas adversidades, não só no plano material como também no plano subjetivo e relacional, onde se deparam com pressões da família e/ou divergentes orientações fornecidas por profissionais de saúde. Contudo, poucos estudos têm sido descritos na literatura junto a esse grupo específico de mulheres, que embora muito investiguem as causas do desmame, são raros aqueles que buscam retratar as atitudes, representações ou o significado que a amamentação tem para a mãe, bem como o que origina a predisposição para amamentar exclusivamente.3-6

No dia-a-dia dos serviços, muitos profissionais de saúde sentem-se freqüentemente impotentes diante das mães que proferem frases como: "Meu leite é fraco"; "Meu patrão não permite que eu fique de licença"; "Meu filho chora muito"; "Minhas mamas vão cair" e outros relatos verbalizados mas, não raro, omitidos - dependendo da relação com os serviços e seus atores - ainda que presentes na subjetividade das mães.

Diante desse dilema, no âmbito da investigação sobre o tema, surge uma indagação central que diz respeito não tanto às causas do desmame, mas ao seu reverso, isto é, experiências bem sucedidas em amamentação, que delineiam a questão: por que algumas mães, mesmo enfrentando situações adversas, apontadas na literatura 2 como "causas de desmame", conseguem superar pressões e dificuldades e amamentar exclusivamente seus bebês até eles completarem seis meses?

Este estudo teve como objetivo proporcionar aos profissionais de saúde, às usuárias do sistema público de saúde, bem como, a outros segmentos envolvidos com a temática focalizada, subsídios para uma compreensão do processo - entendido como construção social - no qual se configura e se sustenta a decisão das mulheres quanto a amamentar ou não seus filhos.

\section{Métodos}

A investigação foi realizada no município de Fortaleza, Ceará, Brasil, utilizando-se a abordagem qualitativa de investigação social, por sua adequação ao estudo de significados, aspirações, crenças e atitudes.?

Buscou-se obter informações suficientes para a reconstrução do universo simbólico das informantes, de modo a permitir uma análise aprofundada das falas, envolvendo a questão central do tema pesquisado. ${ }^{8-9}$

O foco do estudo voltou-se para a busca dos sentidos atribuídos pelas informantes ao fenômeno investigado. Para tanto, adotou-se a perspectiva crítico-interpretativa expressa na hermenêutica filosófica de Hans-Georg Gadamer. ${ }^{10}$

Por fim, esse estudo possui caráter exploratório, haja vista serem ainda muito escassas na literatura produções, empíricas ou conceituais, acerca da questão demarcada, na perspectiva aqui adotada.

A partir dessa fundamentação, são explicitados os passos e os procedimentos adotados, uma vez que tal detalhamento revela-se como requisito de rigor na epistemologia qualitativa. 11

A seleção das mulheres se deu no espaço dos serviços públicos e privados, na cidade de Fortaleza, incluindo duas maternidades públicas, seis unidades básicas e três consultórios privados, através de contatos com os profissionais de saúde que acompanhavam as mães e seus filhos.

Foram identificadas 20 mulheres que atendiam aos critérios e aceitaram participar do estudo, no período de fevereiro a maio de 2004 . No processo de seleção da amostra, ${ }^{8}$ a dificuldade de chegar a esse tamanho amostral deu-se, pelo fato de muitas mulheres relatarem já haver introduzido algum alimento antes de completar os seis meses, o que as excluía do estudo.

Ao final, foram entrevistadas 13 mulheres, divididas em dois diferentes segmentos socioeconômicos, utilizando-se como critério de diferenciação duas faixas de renda familiar: igual/superior e, outra, inferior a três salários mínimos vigentes no período.

As entrevistas foram iniciadas com questões abertas, com temas introdutórios, em geral assuntos do cotidiano, que tinham o objetivo de "aquecimento" inicial para inserção das questões relativas às experiências das mulheres que amamentaram exclusivamente por seis meses. No decorrer do processo, o material discursivo que emergia permitiu o desdobramento de novas questões que passaram a orientar as questões seguintes, garantindo, um procedimento dialético entre o plano empírico e o delineamento teórico. ${ }^{7}$

Vale ressaltar que o processo de recorrência das categorias empíricas nas falas - critério de "exaustão" - levou-nos a concluir a fase de campo 
antes de completarmos as entrevistas com a amostra prevista, de 20 mulheres, dado que o conjunto de 13 entrevistas possibilitou recuperar o universo simbólico focalizado na investigação. As entrevistas seguiram um princípio de "não-diretividade", 10 orientando-se por um eixo decorrente das nossas questões condutoras. Conforme Triviños, (1995:42)12 a construção desse eixo parte de:

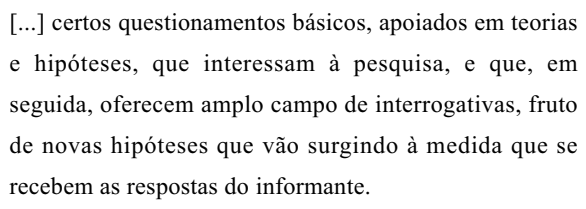

Após a leitura do material arquivado, construiuse o modelo analítico composto por temas e suas categorias, compondo o que, aqui, se nomeia como Rede Interpretativa, 13 para conferir relevo à interface entre as distintas temáticas e suas dimensões. $\mathrm{O}$ texto das entrevistas foi codificado por categorias analíticas e, então, processado, utilizando-se para tal, o programa Ethnograph 4.0. O estudo foi aprovado pelo Comitê de Ética da Universidade Federal do Ceará processo . $^{\circ}$ 011/2004.

O texto interpretativo teve como base, acerca da questão da saúde e do cuidado, demarcações conceituais procedentes de distintos campos disciplinares. Dada a complexidade do fenômeno em questão, o referencial interpretativo contempla concepções relativas ao ato de amamentar, em uma perspectiva histórico-cultural: aspectos apontados como aqueles que predispõem ao desmame, situados nos planos macro e microssocial, dentre os quais ressaltam-se os contextos laboral, familiar, comunitário, bem como os planos da legislação e dos movimentos voltados às garantias em distintas esferas sociais.

Tal constructo interdisciplinar constituiu o referencial teórico prévio às categorias analíticas que embasaram o enfoque hermenêutico desse estudo. No escopo do processo indutivo-dedutivo, foi adotada como alternativa a inserção subseqüente do referencial teórico subjacente às categorias analíticas, ${ }^{14}$ realizando-se um diálogo entre os planos empírico-teórico e vice-versa.

Esta análise indicou uma convergência das categorias empíricas em torno de quatro temas: a) importância do aleitamento materno; b) a decisão de amamentar; c) suporte social e familiar: vivenciando a amamentação; e d) a esfera do trabalho: buscando alternativas. Antes das narrativas, são apresentados dados que caracterizam as mulheres participantes desse estudo, objetivando uma melhor contextualização da produção subjetiva adiante analisada.

\section{Resultados}

\section{Caracterização das informantes}

Foram realizadas entrevistas com 13 mulheres que amamentaram (ou ainda amamentavam) exclusivamente os filhos por um período mínimo de seis meses. A média de idade foi de 28 anos. Quanto ao estado civil, quatro das mulheres eram solteiras (duas delas moravam com o companheiro), oito casadas e uma separada. Agrupamos as mulheres por estrato social, sendo que sete delas tinham uma renda familiar entre dois e três salários mínimos vigentes no período, e seis ganhavam mais de sete salários mínimos, caracterizando, portanto, dois estratos distintos, tal como o pretendido no estudo. A maioria das mulheres (cinco) do grupo socioeconômico mais desfavorecido apresentava um baixo nível de escolaridade (apenas o primeiro grau), enquanto no grupo de nível social mais elevado, cinco concluíram formação em nível superior. Todas as informantes haviam realizado pré-natal, sendo que oito declararam haver recebido alguma informação sobre amamentação no período gestacional.

\section{Percorrendo a rede interpretativa: o olhar das mulheres}

\section{- Importância do aleitamento materno}

A saúde e o desenvolvimento da criança, estão diretamente relacionados ao aleitamento materno exclusivo, pelo menos durante o primeiro ano de vida. 15,16 Contudo, apesar do reconhecimento por muitas mulheres da importância do leite materno, ainda é reduzido o número daquelas que o oferece com exclusividade para o seu filho. ${ }^{17}$

Foi observado, por meio das narrativas obtidas, em ambos os segmentos socioeconômicos, que, para além de fatores de defesa do leite humano para o bebê, há uma associação da amamentação com o vínculo estabelecido entre mãe e filho:

[...] evita também a criança pegar doença porque dizem que a mama é a vacina da criança, então eu decidi dar de mamar até seis meses e é uma forma de carinho, de amor que eu estou passando pro meu filho. (E. 1)

[...] eu me sinto vitoriosa por ter mostrado o lado bom da amamentação, as boas faces e todas as pessoas acabavam vendo assim meus filhos tão saudáveis, tão apegados a mim [...] é bom ver os filhos saudáveis, crescidos com saúde". (E.10) 
Ao lado disso, as mulheres demonstram conhecer as vantagens da amamentação, especialmente na prevenção de diarréias e infecções respiratórias. Vários autores $3,16,17$ se referem a essas vantagens de cunho biológico e diversas propagandas veiculadas nos meios de comunicação apontam benefícios da amamentação, reforçando os aspectos preventivos para o bebê. Ao que parece, esses conteúdos são internalizados e memorizados pelas mães como de suma importância para a saúde dos seus filhos:

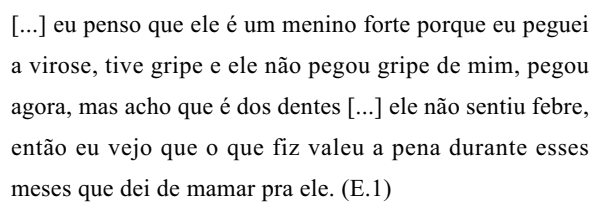

Ah! Eu digo com muito orgulho pras mães que dêem o peito até os seis meses porque vale a pena. Eu tiro hoje pelo meu filho, porque é difícil o menino adoecer, nem uma gripe, não tem de jeito nenhum. Nunca teve diarréia e é uma criança danada demais e eu tenho certeza que isso tudo foi conseqüência já do leite materno. (E.5)

Se por um lado foi revelado, nessas transcrições, o papel pedagógico da mídia e dos profissionais envolvidos na assistência, cabe recuperar que, em décadas anteriores, as mulheres não acreditavam na sua capacidade de ter leite "suficiente" para o bebê ou produzir leite de boa qualidade, por considerá-lo "ralo e fraco", tendo essas construções se alicerçado nesses mesmos atores e veículos. Conforme ressalta a literatura, o padrão de cor e consistência do leite humano foi sendo culturalmente instituído com base nos referenciais estabelecidos para a pecuária leiteira: "leite, para ser forte, tem que ser gordo".,3,18

Apesar da (re)configuração assinalada nas falas anteriores, referentes ao valor do leite materno, essa outra vertente aparece, ainda nos dias de hoje, nos discursos das mulheres, o que permite salientar a forte influência desses conceitos no processo de continuidade da amamentação e como fator determinante na autoconfiança da mulher quanto à sua capacidade de produzir um leite de qualidade. No caso das mulheres abordadas no presente estudo, esses conceitos não se revelam tão fortemente introjetados, apresentando-se em seus discursos questionamentos ao que outrora prevalecia e, ainda atualmente, constitui um tensionamento no que se refere às propriedades do leite materno:

[...] eu sempre tive leite e quanto mais a criança suga o peito da gente mais leite vem e também não tem esse negócio de leite fraco, não sei porque falam isso [...] o meu era muito grosso". (E.1)

[...] eu acho que o leite não é fraco, é produtivo pra criança, traz saúde [...] eu tenho três filhas e todas elas mamaram até sete meses e eu acho que não é fraco o leite materno, ele é muito forte, mas, tem mães que não acreditam. (E.4)

[...] todo mundo dizia que meu leite não ia sustentar, pois ele era muito ralo, mas cada vez que ia no pediatra ele ganhava peso [...] daí, eu pensava comigo mesmo: ele é forte. (E.12)

A amamentação não é vista por essas mulheres apenas como importante para o crescimento e desenvolvimento de um bebê saudável, quer sob o ponto de vista biológico, quer no que tange ao aspecto psíquico (vínculo mãe-filho, por exemplo), mas também para a sua própria saúde, quando previne doenças da mama, pela maior praticidade, bem como evitando outras despesas familiares, aspectos exaustivamente enfatizados nas campanhas e no discurso dos profissionais:

$$
\begin{aligned}
& {[\ldots] \text { é bom pra criança como é bom pra mim }[\ldots] \text { eu achei }} \\
& \text { melhor pros dois. (E.1) }
\end{aligned}
$$

[...] foi ótimo porque eu não gastei nenhum tostão com ele nem em questão de remédio, nem em leite [...] e eu ficava me sentindo muito bem sabendo que ele estava saudável. (E.2)

Embora sejam muito importantes a concepção e o entendimento das mães quanto aos benefícios, praticidade e inúmeras vantagens do aleitamento materno para seus filhos, a informação, por si só, não parece suficiente para garantir a continuidade da amamentação. Muitos outros fatores estão em jogo nessa decisão, conforme se desvela nos temas que se seguem.

\section{- A decisão de amamentar}

$\mathrm{O}$ ato de amamentar é uma função por excelência da mulher e, de acordo com expectativas culturais, constitui-se em momento de realização plena da feminilidade, ainda que com uma forte influência do meio social. Algumas mães passam por situações de incentivo para amamentar exclusivamente, enquanto outras sofrem forte pressão para adotar práticas incorporadas por gerações anteriores, onde o desmame precoce era freqüente. $\mathrm{O}$ que levaria algumas mães a vivenciar esse momento de pleni- 
tude, superando todas as barreiras adversas?

De acordo com Silva (1997: 47): 19

[...] a tomada de decisão em amamentar, ou dar continuidade ao processo, também é baseada nas prioridades identificadas e estabelecidas pela mulher, tendendo ao atendimento das necessidades da criança, que assumem importância [...] os benefícios da criança, identificados pela mãe, anulam aquilo que seria necessidade ou riscos maternos, sendo, a amamentação vista em algum prisma, como benefício para a mulher.

$\mathrm{Na}$ entrevista com as mulheres que amamentaram exclusivamente, foi observada uma motivação interior que as possibilita superar opiniões e pressões contrárias, fazendo com que se sintam seguras quando decidem amamentar os filhos:

[...] com certeza eu sempre quis amamentar e sempre falava assim: eu vou dar de mamar pra ele os seis meses, custe o que custar [...] e ele nunca tomou nem água nos seis meses. (E.6)

[...] foi uma decisão tomada com muita consciência. Desde o início eu decidi que queria amamentar, então qualquer obstáculo que foi aparecendo eu nunca tomei como uma barreira para impedir amamentar, sempre eu considerei como parte do processo e fui continuando, decidindo, decidindo... (E.8).

A tomada de decisão de amamentar aparece, assim, intimamente relacionada aos valores nutricionais do leite, onde também a mãe passa a se responsabilizar em promover e manter a saúde do filho. 20-22 Mas, além disso, a motivação, interesse e persistência, construídos em uma rede de relações, estão sempre presentes, dando suporte aos obstáculos com que se deparam durante o processo de amamentação. Observou-se que alguns acontecimentos vivenciados pelas mulheres entrevistadas no período da infância, ainda no processo de socialização primária, são relembrados no discurso, como um material latente que emerge no momento em que se resgatam aspectos considerados importantes para a compreensão do desejo de amamentar:

[...] olha, é muito difícil assim a gente dizer o que foi que você fez, porque é um trabalho interior, é um trabalho de conscientização, mas eu lembrava sempre da mãe amamentando minha irmã quando eu era pequena, eu via as minhas tias amamentando, e eu pensava, se elas são capazes, porque eu não? (E.2)
[...] eu sempre quis amamentar [...] era bom ver meus irmãozinhos com saúde [...] eu via isso e mexeu muito quando eu lembrava disso. Logo quando eu engravidei eu não tinha dúvida: eu tinha certeza de que ia amamentar... (E.13).

É preciso assinalar a existência de um conjunto de interações estabelecidas na prática da amamentação, subtraídas, tanto no discurso científico como no dos profissionais, os quais, fundamentados na biomedicina, não raro, ocultam o significado dessa experiência para a mulher e o que determina o seu curso. A inadequação desses discursos, muitas vezes veiculados pela mídia, é demonstrada pelo enfoque dado tão somente ao valor nutricional da amamentação. Alguns autores6,15,20,23 consideram as propagandas como veículos de mensagens que abordam especialmente os aspectos biológicos, desconsiderando o aspecto emocional, ao passarem a enfocar a amamentação como algo perfeitamente natural, sem discutir as soluções diante das dificuldades enfrentadas. Foi verificado que no discurso das entrevistadas, a propaganda foi bastante mencionada como um fator colaborador para despertálas para a amamentação:

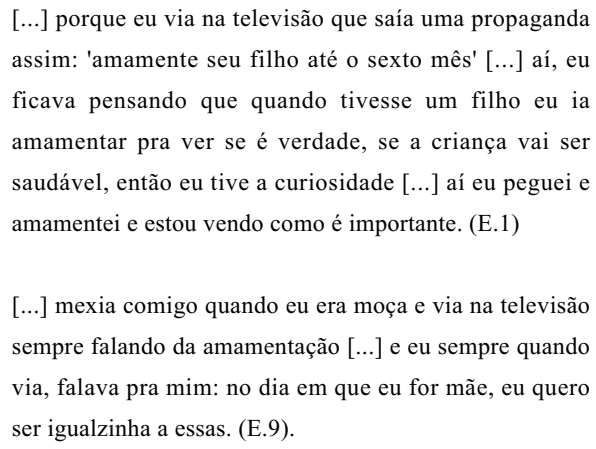

[...] mexia comigo quando eu era moça e via na televisão sempre falando da amamentação [...] e eu sempre quando via, falava pra mim: no dia em que eu for mãe, eu quero ser igualzinha a essas. (E.9).

Pode-se perceber no material até aqui exposto que os elementos determinantes no processo de amamentação ganham sentido no contexto ao qual pertencem em concordância com Silva 19 e Arantes 24 permitem enfatizar que, além do desejo de amamentar um filho, a influência de familiares, amigos e profissionais também é determinante para o sucesso na amamentação, conforme analisado a seguir.

\section{- Suporte social e familiar}

Durante o período da amamentação, a mulher sofre inúmeras influências do entorno social, que interferem, muitas vezes, na decisão de continuar oferecendo o leite materno de forma exclusiva ao filho ou introduzir alimentos complementares. 
A pressão exercida pelos familiares, no contexto analisado nesse estudo, especialmente a das avós e do marido ou companheiro, revela-se como um fator determinante para a continuidade da amamentação ou desmame precoce, à medida que são emitidos julgamentos, provocando na mulher sentimentos de incapacidade, conflitos nas relações familiares, pelas constantes cobranças sobre sua atuação no espaço público.

As opiniões e conselhos, advindos de profissionais de saúde ou das pessoas mais próximas, também constituem elementos que têm forte significado na avaliação que a mãe faz do estado nutricional da criança e da sua capacidade em atender às necessidades do filho. 19,25

\section{- Amamentação: a participação do compa-} nheiro

A presença do companheiro é reconhecida como um auxílio valioso no processo da amamentação, especialmente quando há uma participação mais efetiva nos cuidados diários com a companheira e o filho:

\footnotetext{
[...] eu acredito que ele se sentiu bem do ponto de vista que ele sabia que eu estava fazendo a coisa certa e que ele podia contar com a esposa para beneficiar o filho. No começo ele me ajudava com as massagens para esvaziar um pouquinho e ele fazia isso, ele ficava perto, ele ia pegar o meu filho, ia deixar. (E.8)
}

[...] ele era super carinhoso e olhava o bebê e me ajudava a trazer o bebê pra eu amamentar. (E.4)

Ao compartilhar as tarefas que envolvem cuidados com o filho, a participação do homem é entendida como "ajuda", pelas informantes, nos dois grupos, independentemente da classe social. Essas práticas oferecem aos pais a oportunidade do cuidado com o bebê, estimulando-os a sentir a amamentação não apenas como uma exclusividade da mãe mas, ao mesmo tempo, compartilhar as responsabilidades assumidas pelo casal:

[...] eu não recordo de nenhum dos filhos eu ter levantado nenhuma vez para pegar (o filho); à noite quando chorava, ele ia pegar, botava pra eu amamentar [...] então ele só não amamentou porque não tinha leite. (E.13)

[...] porque além de eu dar de mamar, ele fíca beijando o filho dele, ele acha super bonito, se a criança chora, ele diz pra eu pegar a criança e botar no peito e se fica chorando ele fica brincando com ele, ele é assim... (E.2)
A experiência de algumas mulheres sem companheiro, analisadas nos dois segmentos socioeconômicos, caracteriza-se como um elemento de interferência, especialmente quando elas têm que lidar com a responsabilidade no cuidado exclusivo com o filho, influenciando implicitamente o curso da amamentação. A interpretação dessa experiência, determinada pelos sentimentos, resulta na percepção da sensação de prazer ou de contrariedade em relação a amamentar:

\footnotetext{
É muito difícil você criar um filho sozinha! Você não ter o amor do pai perto, mas minha família me ajudou muito, graças a Deus, e tive muita força aqui das meninas, minhas companheiras de trabalho, aqui do hospital. Acho que isso me fez seguir em frente. É muito bom você ter ajuda de uma pessoa, principalmente, porque eu não tinha o pai do meu lado e para mim foi difícil. (E.6)
}

Eu saí do hospital com quatro dias e no quinto dia, ele desapareceu e passou quinze dias sem ninguém saber o paradeiro dele $[\ldots]$ então para um começo de um resguardo. (E.7)

Entretanto, algumas mulheres que moram com o companheiro também vivenciam momentos de intranqüilidade, quando não recebem o apoio esperado, gerando medo de não produzir leite ou de continuar a amamentação:

\footnotetext{
[...] foi difícil porque eu ficava dizendo eu vou, mas tinha aquela pessoa [...] e eu pensei até em tirar o peito porque o menino tava chorando e o marido também entrava junto com a mãe dele, porque ele escutava a mãe dele e mandava eu dar porque o bichinho tá chorando, mais foi difícil, foi uma decisão mesmo. (E.11)
}

[...] muito difícil, a gente se sente nada mesmo [...] eu não gosto nem de falar, eu pensei até que fosse ter problema no leite porque dizem que quando a gente fica assim, o leite seca e realmente tem dias que reduziu, mas, mesmo assim, eu fui estimulando. (E.7)

É importante destacar que apesar de se considerar o nascimento de um filho como um fato relevante e de grande transformação na vida do casal, alguns homens têm uma reação que se configura pelo ciúme e pelo sentimento de estar sendo deslocado dentro do contexto familiar. Vários autores 22,24 assinalam que muitos homens apresentam esse sentimento por não conseguirem oferecer o alimento da mesma forma que a mulher ou por não assimilarem a reconfiguração do contexto familiar: 
[...] ele é muito ciumento; diz que depois que eu tive a menina eu só passei a cuidar dela e não cuido dele [...] aí, hoje ele não fala mais comigo, eu não moro na casa dele, ele não tem mais nada comigo. (E.3)

[...] ele ficava um pouquinho enciumado quando eu queria me preocupar mais com o bebê que tava amamentando do que com ele no momento que ele também queria um carinhosinho [...] era que ele achava que eu só queria meus peitos pro meu filho. (E.10)

Acrescentam, alguns autores, que a existência de outros conteúdos subjetivos ou até mesmo inconscientes levam o homem a rejeitar, nas interações sexuais, contatos físicos com a mama, os quais podem ter sido originados no plano cultural carregado de conteúdos moralistas. 22,24,26,27

Vale ressaltar que os sentimentos de tensão, ciúme e insegurança na função de alimentar o filho e atender ao papel de esposa, também é vivenciado pela mulher e se expressa no discurso das informantes:

Ele mudou e, na verdade, eu fiquei com um pouco de ciúme porque ele ficava mais pro lado do bebê $[\ldots]$ aquela coisa toda, Aí, esqueceu um pouquinho de mim e, aí, fiquei com ciúmes. Mas eu fiquei falando pra ele que olhasse um pouquinho pra mim que a criança já tava ali e já tava cuidando e pronto, era o primeiro filho também. (E.6)

[...] eu queria que ele entendesse que agora sou mãe e falava isso sempre pra ele [...] queria que ele tivesse mais paciência até ela ficar mais grandinha. (E.9)

O envolvimento do pai apresenta-se, então, como um elemento fundamental, pois ao desempenhar um papel de participante no processo da amamentação, aumenta o suporte oferecido à companheira e ao bebê, ao mesmo tempo em que se reconhece como um elemento importante, partícipe e cúmplice na sua função de "novo pai".

\section{- A importância fundamental das avós}

Durante algumas décadas do século $\mathrm{XX}$ as mulheres sofreram uma forte influência do marketing produzido pelas indústrias, incentivando o desmame precoce, através de propagandas que consideravam o leite "fraco", insuficiente para atender as necessidades do bebê e contextualizando a amamentação como um fator responsável pela flacidez das mamas, dentre outros aspectos desfavoráveis à prática. 15,20,28 Isso se transformou em problema, a partir do momento em que a falta de informação correta proporcionou uma geração de mulheres que desacreditaram no leite materno como fonte exclusiva de alimento. Considerando-se que essas mulheres, nos diferentes segmentos socioeconômicos, em sua grande maioria, são avós nos dias de hoje, há uma tendência ao repasse das informações adquiridas a essa nova geração.

Contudo, apesar dessa pressão negativa, foi interessante observar que algumas nutrizes percebiam claramente essas interferências no processo de tomada de decisão de parar ou não a amamentação:

[...] minha mãe me falava, porque minha mãe não amamentou os filhos dela porque o leite virou água. Aí, ela disse que o leite dela era muito fraquinho. (E.2)

[...] eu tive também dificuldade porque a minha família, a minha mãe não queria que eu amamentasse porque eu trabalhava e dizia que o menino ficava com fome e era pra eu dar o mingau que era mais forte e engordava mais [...] mas aí, eu sofri porque eu chorava de um lado e queria amamentar e eles não queriam deixar, mas eu consegui. (E.5)

[...] ela disse que tinha criado sete e nunca tinha dado de mamar e tava tudo aí. (E.6)

A minha sogra ligava de um outro estado dizendo: 'não se culpe se você não conseguir amamentar porque o meu também era uma criança muito grande e ele começou a dormir quando eu dei mingau. (E.8)

Por outro lado vale considerar que, em alguns casos, as avós também desempenham um papel muito importante no processo de incentivo à amamentação, muitas vezes por reconhecerem que lhes faltaram informações suficientes para que prolongassem o aleitamento materno e por considerarem o leite materno como um elemento fundamental para a saúde e o desenvolvimento do bebê:

[...] a minha mãe e meu pai sempre deram a maior força, porque, naquele tempo, não tinha ninguém que aconselhasse, mas agora não, ela me aconselhou a dar de mamar até seis meses. (E.1)

[...] aí, ela disse que queria uma filha que amamentasse o neto dela. Ela dizia: ' [...] minha filha amamente porque seu filho vai ficar sempre saudável e vai ficar muito apegado com você e quando os dentinhos dele nascer ele não vai ter diarréia; a amamentação pra ele vai ser sempre importante na vida dele". (E.2) 
$\mathrm{O}$ apoio fornecido pelas avós e familiares, quando presente, é claramente percebido pelas mulheres entrevistadas, como um elemento facilitador para a continuidade da amamentação aos seis meses, especialmente quando há uma transmissão do aprendizado anterior para a filha:

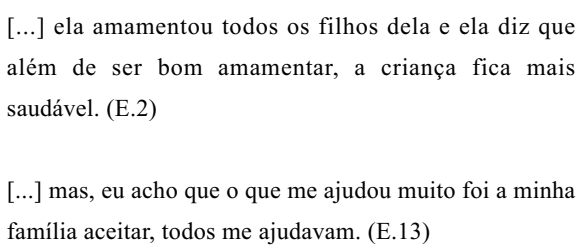

Em síntese, a mulher, durante o período da amamentação, apresenta-se vulnerável às opiniões e conselhos das pessoas com as quais interage em seu meio, seja o marido, avós, familiares. Esses são personagens que avaliam a situação apresentada no cotidiano compartilhado e através da interação mãe e filho, emitindo o seu julgamento. Mas, os obstáculos não param por aí: a esfera do trabalho e a dificuldade de conciliar diferentes funções e expectativas revelaram-se como uma verdadeira barreira, para muitas mulheres, intransponível, embora haja aquelas que conseguiram ultrapassá-la.

\section{A esfera do trabalho: superando dificuldades, buscando soluções alternativas}

Decidir parar as atividades profissionais ou os estudos, ainda que temporariamente, tem sido uma alternativa encontrada por algumas mulheres que priorizam os cuidados com o filho, considerando ser essa atitude fundamental para a continuidade da amamentação. 17,29 Contudo, há que se reconhecer que essa alternativa nem sempre é possível, seja por motivos objetivos, seja por aspectos subjetivos.

$\mathrm{Na}$ entrevista com as mulheres participantes da investigação, foi constatado que algumas delas buscam solucionar o impasse, envolvendo familiares para colaborar na administração do leite materno que é estocado previamente à saída da mãe para atividades externas ou "sacrificam" um pouco a vida rotineira para amamentar com exclusividade:

[...] eu tinha que decidir entre continuar estudando ou dar de mamar [...] não teve jeito, eu pensei nele e parei um ano pra dar de mamar e não me arrependo, ainda sou nova.... (E.5)

[...] eu tive a oportunidade de ficar um pouco em casa cuidando deles, então nas três oportunidades, eu amamentei $[\ldots]$ na primeira eu saía pra faculdade, depois pro meu trabalho, pois eu não tive licença maternidade, mas, mesmo assim, amamentei por seis meses. (E.10)

[...] eu trabalhava só num emprego nessa época e tinha dois plantões só na semana, então eu tinha muito pouco tempo fora de casa, então eu fazia ordenha do leite e colocava na mamadeira e conservava na geladeira e pedia para a minha irmã dar no lugar do suco. Às vezes, era um sufoco, mas eu queria muito dar de mamar! (E.11)

O trabalho vem sendo apontado na literatura como um dos principais obstáculos para a continuidade da amamentação, uma vez que os benefícios trabalhistas aferidos pela legislação não são implementados.3,15,27 Isso gera uma série de incertezas à mulher, desde quando engravida, pois ter que organizar a sua vida no trabalho e no lar, muitas vezes, a força a largar ou perder o emprego para continuar a amamentação. Caso contrário, terá que desistir ou encontrar estratégias para prolongar a amamentação.

[...] olha não foi fácil chegar até seis meses [...] tinha horas que dava vontade de parar, pois minha patroa deixava eu sair antes das $2 \mathrm{~h}$, mas, às vezes, eu ficava nervosa pra tirar o leite e o bichinho ficava chorando até eu chegar, mas deu certo. Graças a Deus! (E.4)

[...] eu só sinto revolta por não ter conquistado o direito de ter licença que é um direito garantido pela Constituição, mas o fato de eu ter trabalhado não atrapalhou na amamentação em hipótese alguma. Naquele momento, se eu não podia, alguém levava minha filha no posto e eu amamentava. Eu tinha todo aquele cuidado de lavar as mãos e me preparar toda [...] dou um conselho: é a coisa mais fácil do mundo. (E.8)

[...] eu ia pro posto, mas eu tinha um celular e na hora que minha filha acordava, eu deixava sete horas ela dormindo e ela dormia até às dez e eu ficava mais ou menos controlando $[\ldots]$ então quando ela se mexia telefonavam pro meu celular e eu tinha carro e imediatamente estava em casa, em questão de quinze minutos [...] eu preparei um certa estrutura pra amamentar. (E.10)

Os empregadores, na sua grande maioria, não disponibilizam opções às mulheres trabalhadoras, de modo a facilitar a continuidade do aleitamento para os filhos. Acrescente-se que, mesmo com garantias no plano legal, onde a mulher tem direito a 120 dias de licença maternidade, reduz-se a oferta de emprego a esse grupo, causando receio às trabalhadoras, aspecto que as obriga a retornar às suas atividades antes do tempo previsto, pelo medo de perder o emprego. 5,17 
Indo ao encontro do que aponta a literatura, constatamos na fala das informantes desse estudo que o trabalho representa uma grande barreira, especialmente considerando que nas camadas mais pobres - com características mais informais de emprego (trabalho sem registro), a mãe se vê obrigada a precocemente desistir do aleitamento materno exclusivo, para permitir a sobrevivência dela e do filho. Isso assim ocorre pelo fato de haver um desrespeito à condição de lactante, inserindo, portanto, a discussão no âmbito da temática da construção da cidadania no campo da saúde.

\section{Considerações finais}

A maioria dos trabalhos na literatura focaliza as causas e conseqüências do desmame precoce, mostrando apenas a decisão final obtida, muitas vezes sem esclarecer os reais motivos que levaram as mães a interromper a oferta do leite materno como alimento exclusivo. A avaliação dos dados epidemiológicos disponíveis, permite reafirmar a questão do desmame precoce como problema de saúde pública, ressaltando-se a multidimensionalidade do fenômeno, cuja solução não depende de um fator isolado, tal como, muitas vezes, pressupõem as instituições responsáveis pela formulação e implementação de intervenções voltadas ao equacionamento do problema.

Fica evidente a necessidade de serem propostas alternativas mais viáveis às mulheres lactantes, sendo indispensável, para tanto, além de esclarecimento sobre as vantagens que o leite materno proporciona, o apoio social, familiar, político e institucional.

Neste estudo os depoimentos de 13 mulheres que conseguiram obter êxito com a amamentação, leva a refletir, essencialmente, sobre a reavaliação e redefinição das atitudes e estratégias que vêm sendo adotadas para incentivar a prática do aleitamento materno exclusivo.

$\mathrm{Na}$ análise das narrativas foi constatado que o sucesso da amamentação originou-se, principalmente, no significado construído pelas mesmas mulheres durante toda a vida cotidiana, período em que foram absorvendo e reinterpretando concepções estabelecidas antes e durante suas experiências com a amamentação. Dessa forma, a motivação e as percepções acerca do processo de amamentar são construídas através de experiências na família e, principalmente, pela forte determinação para levá-lo adiante, desencadeando a possibilidade de lactar e superando as diferentes adversidades que surgem como possíveis obstáculos à amamentação. Dentre essas experiências, destacaram-se as figuras dos companheiros/pais, bem como a das avós, estas últimas funcionando, muitas vezes, como elementos multiplicadores da influência negativa exercida pela propaganda das indústrias de alimentos infantis, especialmente, nas décadas de 60 e 70, no Brasil.

É importante, portanto, enfatizar que o papel desempenhado pelos pais e avós é central no processo, sendo fundamental que os serviços de prénatal e pós-parto possam envolvê-los, incentivandoos e valorizando-os quanto à sua participação e colaboração no apoio à mulher, para o estabelecimento do aleitamento materno.

Cabe ao Estado e à sociedade assegurar à mulher condições indispensáveis para que o objetivo de prolongar o aleitamento materno por um período mínimo de seis meses se concretize: segurança e apoio no emprego durante a gravidez e no pós-parto; instalação de creches e de locais de aleitamento no trabalho; desmistificação da separação de papéis sociais homem e mulher no contexto familiar,eliminando a dupla jornada hoje exercida pela mulher trabalhadora.

Em suma, é essencial que o profissional de saúde entenda o seu papel como esclarecedor, conscientizador e motivador, mas, como os demais atores, coadjuvante, já que a decisão de amamentar será, em última instância, sempre da mãe, entendendo-se esse ato como resultante de uma rede de aspectos situados nos planos macro e micro da vida social.

\section{References}

1. WHO (World Health Organization). World Health Assembly: infant and young child nutrition. Geneva; 2001. (Resolution WHA, 54.2)

2. Brasil. Ministério da Saúde. Avaliação das ações executadas em aleitamento materno no ano de 2002: relatório. Brasília, DF; 2002

3. Ichisato SMT, Shimo AKK. Revisitando o desmame precoce através de recortes da história. Rev Latino-am Enfermagem. 2002; 10: 578-85
4. Escobar AMU, Ogawa AR, Hiratsuka M, Kawashita MY, Teruya PY, Grisi S, Tomikawa SO. Aleitamento materno e condições socioeconômico-culturais: fatores que levam ao desmame precoce. Rev Bras Saúde Matern Infant. 2002; 2: 253-61.

5. Osis MJD, Duarte GA, Pádua KS, Hardy E, Sandoval LM, Bento SF. Aleitamento materno exclusivo entre trabalhadoras com creche no local de trabalho. Rev Saúde Pública. 2004; 38: 172-9. 
6. Coutinho SB, Lima MC, Ashworth A, Lira PIC. Impacto de treinamento baseado na Iniciativa Hospital Amigo da Criança sobre práticas relacionadas à amamentação no interior do Nordeste. J Pediatr. (Rio J) 2005; 81: 471-7.

7. Bosi MLM, Mercado FJM. Pesquisa qualitativa de serviços de saúde. Petrópolis: Vozes; 2004.

8. Tesch R. Qualitative research: analysis, type \& software tools. New York: The Falmer Press; 1995.

9. Bosi MLM, Mercado FJM. Avaliação qualitativa de programas de saúde: enfoques emergentes. Petrópolis: Vozes; 2006

10. Gadamer HG. A extensão da questão da verdade à compreensão nas ciências do espírito. Petróplis: Vozes; 1997.

11. Denzin NK, Lncoln D. Handbok of qualitative research. California: Sage Publication; 2002.

12. Triviños ANS. Introdução à pesquisa em ciências sociais.: a pesquisa qualitativa em educação. São Paulo: Atlas, 1990.

13. Kandel L. Reflexões sobre o uso da entrevista, especialmente a não-diretiva, e sobre as pesquisas de opinião. In: Thiollent M. Crítica metodológica, investigação social em enquete operária. São Paulo: Polis; 1980. p. 25-26.

14. Creswell JW. Research design. Qualitative \& quantitative approaches. London: Sage; 1994.

15. Silva AP, Souza N. Prevalência do aleitamento materno. Rev Nutr. 2005; 18: 301-10.

16. Santos VLF, Soler ZASG, Azoubel R. Alimentação de crianças no primeiro semestre de vida: enfoque no aleitamento materno exclusivo. Rev Bras Saúde Matern Infant. 2005; 5: 283-91.

17. Rea MF. Reflexões sobre a amamentação no Brasil: de como passamos a 10 meses de duração. Cad Saúde Pública. 2003; 19 (Suppl 1): 37-45.

18. Sandre-Pereira G, Colares LGT, Carmo MGT, Soares EA. Conhecimentos maternos sobre amamentação entre puérperas inscritas em programa de pré-natal. Cad Saúde Pública. 2000; 16: 457-66.
19. Silva IA. Amamentar: uma questão de assumir riscos ou garantir benefícios. São Paulo: Robe; 1997.

20. Almeida JAG, Novak FR. Amamentação: um híbrido natureza-cultura. J Pediatr. (Rio J) 2004; 80: 119-25.

21. Venancio SI, Monteiro C. A tendência da prática da amamentação no Brasil nas décadas de 70 e 80 . Rev Bras Epidemiol. 1998; 1: 40-9.

22. Vieira GO, Almeida JAG, Silva LR, Cabral VA, Santana Netto PV. Fatores associados ao aleitamento materno e desmame em Feira de Santana, Bahia. Rev Bras Saúde Matern Infant. 2004; 4: 43-150.

23. Araújo MFM, Del Fiaco A, Werner EH, Schmitz BAS. Incentivo ao aleitamento materno no Brasil: evolução do Projeto Carteiro Amigo da Amamentação de 1996 a 2002. Rev Bras Saúde Matern Infant. 2003; 3: 195-204.

24. Arantes CIS. O fenômeno da amamentação: uma proposta compreensiva [dissertação mestrado]. Ribeirão Preto: Escola de Enfermagem da Universidade de São Paulo; 1991

25. Giugliani ERJ, Victora CG. Normas alimentares para crianças brasileiras menores de dois anos: bases científicas. Washington, DC: OPAS; 1997.

26. Chandran L, Gelfer P. Breastfeeding: the essential principles. Pediatr Rev. 2006; 27: 409-1

27. Scavenius M, Van Hulsel L, Meijer J, Wendte H, Gurgel R. In practice, the theory is different: a processual analysis of breastfeeding in northeast Brazil. Soc Sci Méd. 2007; 64: $676-88$

28. Kummer S, Giugliani ERJ, Susin LO, Folletto JL, Lermen NR, Wu VYJ, Santos L, Caetano MB. Evolução do padrão de aleitamento materno. Rev Saúde Pública. 2000; 34: 143-

29. Nakamura SS, Veiga KF, Ferrarese SRB, Martinez FE. Percepção e conhecimento de meninas escolares sobre o aleitamento materno. J Pediatr. (Rio J) 2003; 79: 181-8.

Recebido em 10 de julho de 2006

Versão final apresentada em 6 de outubro de 2007

Aprovado em 17 de novembro de 2007 